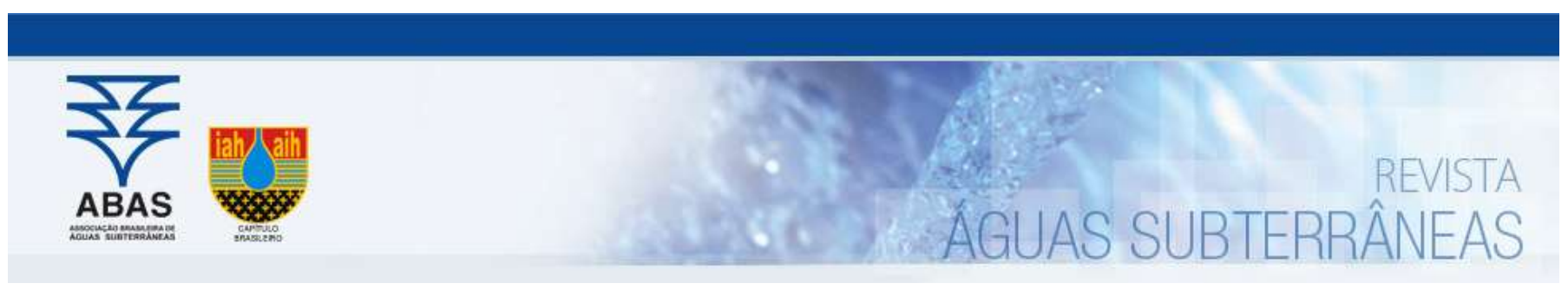

Estudos de Caso e Notas Técnicas

\title{
Avaliação da vulnerabilidade intrínseca a contaminação do aquífero cárstico Salitre no município de Cafarnaum, Bahia
}

\section{Evaluation of intrinsic vulnerability the contamination of the karst aquifer in Cafarnaum region, Bahia}

\author{
Rodolfo Santos Gasser1; Manoel Jerônimo Moreira Cruz2; Manuel Vitor Portugal Gonçalves² ${ }^{\bowtie}$ \\ ${ }_{1}$ POSPETRO - Programa de Pós-Graduação em Geoquímica: Petróleo e Meio Ambiente, Universidade Federal da Bahia (UFBA), Salvador, \\ BA \\ 2 Universidade Federal da Bahia (UFBA), Salvador, BA \\ $\bowtie$ rodolfogasser@yahoo.com.br, jc9508@gmail.com, zoovitor81@yahoo.com.br
}

Resumo

Palavras-chave:

Aquífero cárstico. Vulnerabilidade.

Método COP.

\begin{abstract}
O aquífero cárstico Salitre situa-se na Bacia Carbonática de Irecê, na região centro-norte da Bahia, no contexto geológico da Formação Salitre. É constituído por espessas sequências de calcarenitos, calcilutitos, calcissiltitos e dolomíticos intercalados, por vezes, com sequências terrígenas subordinadas, constituídas por silexitos, arenitos, siltitos, laminitos e margas. 0 objetivo principal do estudo é avaliar a vulnerabilidade intrínseca natural à contaminação do aquífero cárstico Salitre, no município de Cafarnaum, para isso usou-se a metodologia COP. Os aquíferos cársticos são especialmente vulneráveis à contaminação devido a sua pouca profundidade, a alta velocidade do fluxo de água, a sua conexão direta com a superfície e a sua recarga através de formas de absorção abertas. Para a avaliação da vulnerabilidade natural do aquífero cárstico à contaminação através da metodologia COP, levam-se em consideração três parâmetros hidrogeológicos: concentração do fluxo, camadas sobrepostas e regime de precipitação. A análise do mapa de vulnerabilidade intrínseca a contaminação, permitiu a delimitação de 4 classes de vulnerabilidade na área: muito alta $\left(12,5 \%-70,20 \mathrm{~km}^{2}\right)$, alta $\left(0,7 \%-4,0 \mathrm{~km}^{2}\right)$, moderada $\left(28,0 \%, 154,41 \mathrm{~km}^{2}\right)$ e baixa $(58,7 \%, 330,00$ $\mathrm{km}^{2}$ ). A individualização das feições cársticas e de sua área de influência é o fator que teve um papel significativo para a delimitação da classe de vulnerabilidade muito alta.
\end{abstract}

Abstract

Keywords:

The Salitre karst aquifer is located in the Sedimentary Carbonic Basin of Irecê, in the north-central region of Bahia, in the geological context of the Salitre Formation. It consists of thick sequences of calcarenites, calcilutites, calcissiltites and dolomites intercalated sometimes with subordinate continental sequences, constituted by silexites, sandstones, siltites, mudstones and marls. The main objective of the study is evaluate the intrinsic vulnerability to the natural contamination of the karst aquifer in Cafarnaum region, applying the COP methodology. It is well know that karstic aquifers are especially vulnerable to contamination due to their shallow depth, the high velocity of water flow, their direct connection to the surface and their recharge through open absorption forms. For the assessment of the natural vulnerability of the karst aquifer to contamination through the POP methodology, three hydrogeological parameters are considered: flow concentration, overlapping layers and precipitation regime. The analysis of the vulnerability map intrinsic to the contamination allowed the delimitation of four classes of vulnerability in the area: very high $(12.5 \%$ $\left.70.20 \mathrm{~km}^{2}\right)$, high $\left(0.7 \%-4.0 \mathrm{~km}^{2}\right)$, moderate $\left.28.0 \%, 154.41 \mathrm{~km}^{2}\right)$ and low $\left(58.7 \%, 330.00 \mathrm{~km}^{2}\right)$. The individualization of the karstic features and their area of influence is the factor that played a significant role in the delimitation of the very high vulnerability class.

DOI: http://dx.doi.org/10.14295/ras.v32i1.29090

\section{INTRODUÇÃO}

As regiões cársticas são áreas de enorme interesse econômico e hidrogeológico, dado que, possuem solos férteis, não apresentam drenagem superficial, exibem relevo pouco acidentado, possuem valiosas reservas de água no subsolo e têm grande importância ambiental. Aproximadamente 20 a $25 \%$ da população mundial dependem parcialmente ou totalmente de recursos hídricos proveniente de aquíferos cársticos (FORD; WILLIAMS, 2007) e devido às características especiais dos sistemas cársticos, a qualidade desta água pode ser facilmente degradada como resultado de impactos antrópicos (IVÁN; MÁDL-SZÕNYI, 2017). 
Vrba e Zaporozec (1994) definem a vulnerabilidade como uma propriedade intrínseca do sistema de água subterrânea que depende da sensibilidade do mesmo aos impactos humanos e/ou naturais. A vulnerabilidade de um aquífero é caracterizada por meio dos seguintes fatores naturais: a) acessibilidade da zona saturada à penetração de poluentes, b) capacidade de atenuação resultante da retenção físico-química ou reação ao poluente na zona não saturada e, c) a diluição e a remobilização dos contaminantes (FOSTER et al., 2002).

Para a avaliação da vulnerabilidade natural do aquífero cárstico a contaminação, leva-se em consideração quatro fatores naturais: concentração de fluxo, camadas de proteção, regime de precipitação e, desenvolvimento da carste. A metodologia COP, desenvolvida por Vías et al. (2006), usada para avaliar a vulnerabilidade intrínseca do aquífero Salitre em Cafarnaum, considera três parâmetros hidrogeológicos: concentração do fluxo (C), camadas de proteção $(0)$, e precipitação $(P)$.

\section{CARACTERIZAÇÃO DA ÁREA DE ESTUDO}

A área de estudo pertence ao município de Cafarnaum, que está situado no centro norte do estado da Bahia e situa-se a $430 \mathrm{~km}$ de Salvador. Está situada na faixa climática do semiárido conforme a Superintendência de Estudos Econômicos (SEI, 2011), com uma pluviosidade média anual de $503,3 \mathrm{~mm}$, com período chuvoso de novembro a março e temperatura média anual de $22,2{ }^{\circ} \mathrm{C}$.

Localiza-se na Bacia Carbonática de Irecê, por sua vez, inserida na porção norte do Cráton do São Francisco. Afloram na bacia as rochas do Complexo Xique-Xique (embasamento cristalino), de idade Paleoproterozoica, seguido por rochas do Supergrupo Espinhaço, de idade Mesoproterozoica, e do Supergrupo São Francisco de idade Neoproterozoica, além da presença de Coberturas Fanerozoicas Tércio-Quaternárias (INDA; BARBOSA, 1978) (Figura 1).

O Grupo Una, de acordo com Pedreira et al. (1987), é composto pela Formação Bebedouro na base e Formação Salitre no topo. A Formação Bebedouro é constituída por diamictitos, pelitos e arenitos, estratificados e maciços, depositados sob influência glacial (DOMINGUEZ, 1996; GUIMARÃES, 1996; FIGUEIREDO, 2008). Ocorre em superfície de maneira localizada e descontínua, restrita às bordas da bacia. Recobrindo os sedimentos glaciogênicos da Formação Bebedouro, houve a deposição de uma espessa sucessão carbonática plataformal da Formação Salitre, tendo sido depositada em uma bacia formada no contexto de um mar epicontinental (DOMINGUEZ, 1993). Misi, (1979); Pedreira et al. (1987) e Sampaio et al. (2001), descreveram a Formação Salitre como uma formação constituída por espessas sequências de calcarenitos, calcilutitos, calcissiltitos e dolomitos intercalados, por vezes, com sequências terrígenas subordinadas constituídas por silexitos, arenitos, siltitos, laminitos e margas.

Guerra (1986) caracterizou o comportamento hidrogeológico do aquífero cárstico Salitre como sendo de grande capacidade de recarga e elevada velocidade de fluxo subterrâneo, sobretudo através da rápida percolação da água por meio das formas de absorção do aquífero, como sumidouros, dolinas e fraturas. Nossa (2011) classificou o aquífero cárstico Salitre como anisotrópico, com condutividade hidráulica variável de acordo com a densidade de fraturas, podendo ser considerado como um aquífero livre, em função da baixa espessura dos solos na área e que descontinuidades laterais e verticais da transmissividade, pode ocasionar a formação de aquíferos isolados.

\section{MATERIAIS E MÉTODOS}

\subsection{Metodologia COP}

O método COP desenvolvido por Vías et al. (2006), baseia-se nos argumentos da Ação Europeia COST 620 (ZWHALEN, 2004) sobre avaliação da vulnerabilidade de aquíferos cárstico à contaminação. Esse método considera três parâmetros hidrogeológicos para avaliar a vulnerabilidade intrínseca de aquíferos cársticos à contaminação: Concentração do fluxo (C), Camadas de proteção (O), e Precipitação (P) (Figura 2).

O fator (C) representa a vulnerabilidade do aquífero à contaminação, em função da infiltração da água através da camada de proteção, ou seja, representa o potencial da água de ignorar a proteção fornecida pelas camadas sobrepostas. Dessa forma, este fator representa o grau que a precipitação atravessa a zona não saturada e infiltram no interior do aquífero cárstico. Dois cenários podem ocorrer na análise desse fator:

- Cenário 1 - Este descreve a situação que a bacia é coberta por finas camadas de baixa permeabilidade, em que a infiltração acontece de forma concentrada através das feições cársticas (sumidouros e/ou dolinas), ou seja, o fluxo penetra facilmente pela zona não saturada e infiltra no aquífero. A avaliação do fator $(\mathrm{C})$ neste cenário considera quatro variáveis: a distância das áreas de recarga para as áreas de sumidouros (dh) e dolinas (ds) e a influência da declividade (s) e da vegetação (v). A vulnerabilidade do aquífero diminui com o aumento da distância entre as áreas de recarga e as dolinas e sumidouros. A avaliação da cobertura vegetal considera a percentagem de cobertura da área pela vegetação que influi diretamente no regime infiltração-escoamento. A declividade subdivide-se em quatro classes e correlaciona-se com a presença ou ausência da cobertura vegetal e essa combinação origina o parâmetro (sv). Os valores sv demonstram que quando a declividade aumenta, a vegetação tende a ser mais escassa e a vulnerabilidade tende a aumentar.

- Cenário 2 - Este descreve a situação onde a infiltração ocorre de forma difusa, podendo ser através de fraturas. A avaliação do fator (C) neste cenário é avaliada pela combinação de três variáveis: feições superficiais (sf), declividade (s) e vegetação (v). A variável feições superficiais (sf) considera características geomorfológicas específicas para rochas carbonáticas e a presença ou ausência de camadas de recobrimento (permeáveis ou impermeáveis), as quais determinam a importância dos processos de escoamento superficial e/ou infiltração atuantes na área. A variável vegetação e declive (sv) neste cenário possui o valor oposto do cenário 1 , ou seja, quanto mais íngreme e consequentemente menos vegetação, a água escoa para longe do aquífero. 
Nas zonas com infiltração concentrada através de dolinas e sumidouros a proteção natural dada pelo fator 0 é ignorada, por causa dos baixos valores atribuídos ao fator $\mathrm{C}$. Por outro lado, onde a infiltração difusa ocorre na ausência de características cársticas, então o aquífero mantém alguma proteção natural atribuída ao fator 0 .
O fator (0) considera a proteção fornecida para o aquífero em função de propriedades físicas, como textura e litologia e espessura das camadas acima da zona saturada. Para a avaliação do parâmetro (0) é considerado o subfator solo [Os] e subfator litologia das camadas da zona insaturada [OI].

Figura 1 - Mapa e perfil geológicos simplificados da Bacia de Irecê e adjacências, mostrando a área em estudo no retângulo vermelho.

(B) Cráton do São Francisco e faixas marginais

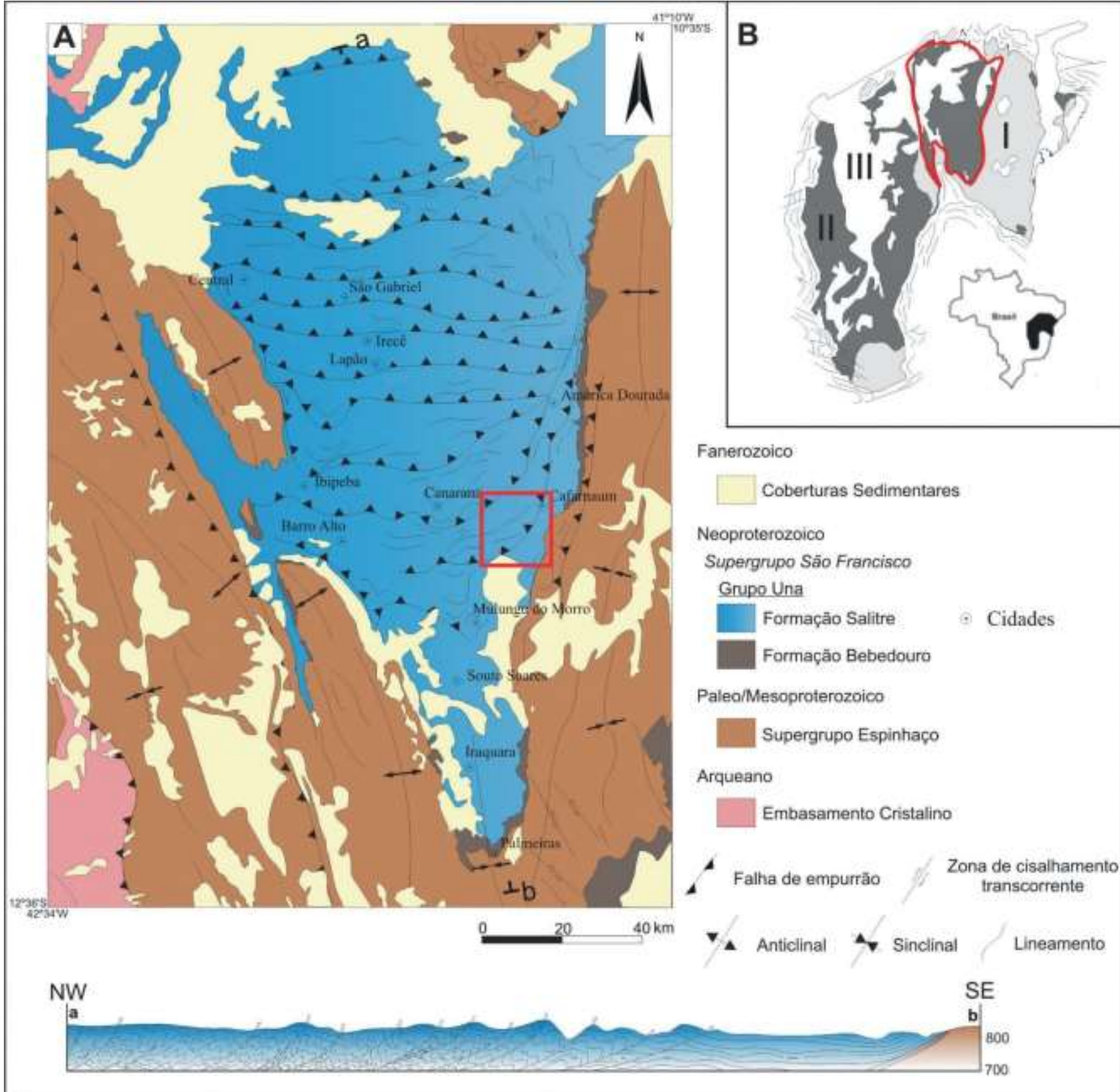

Fonte: Santos (2017) 
Figura 2 - Diagrama do método COP, mostrando a diferenciação dos fatores C, O e P

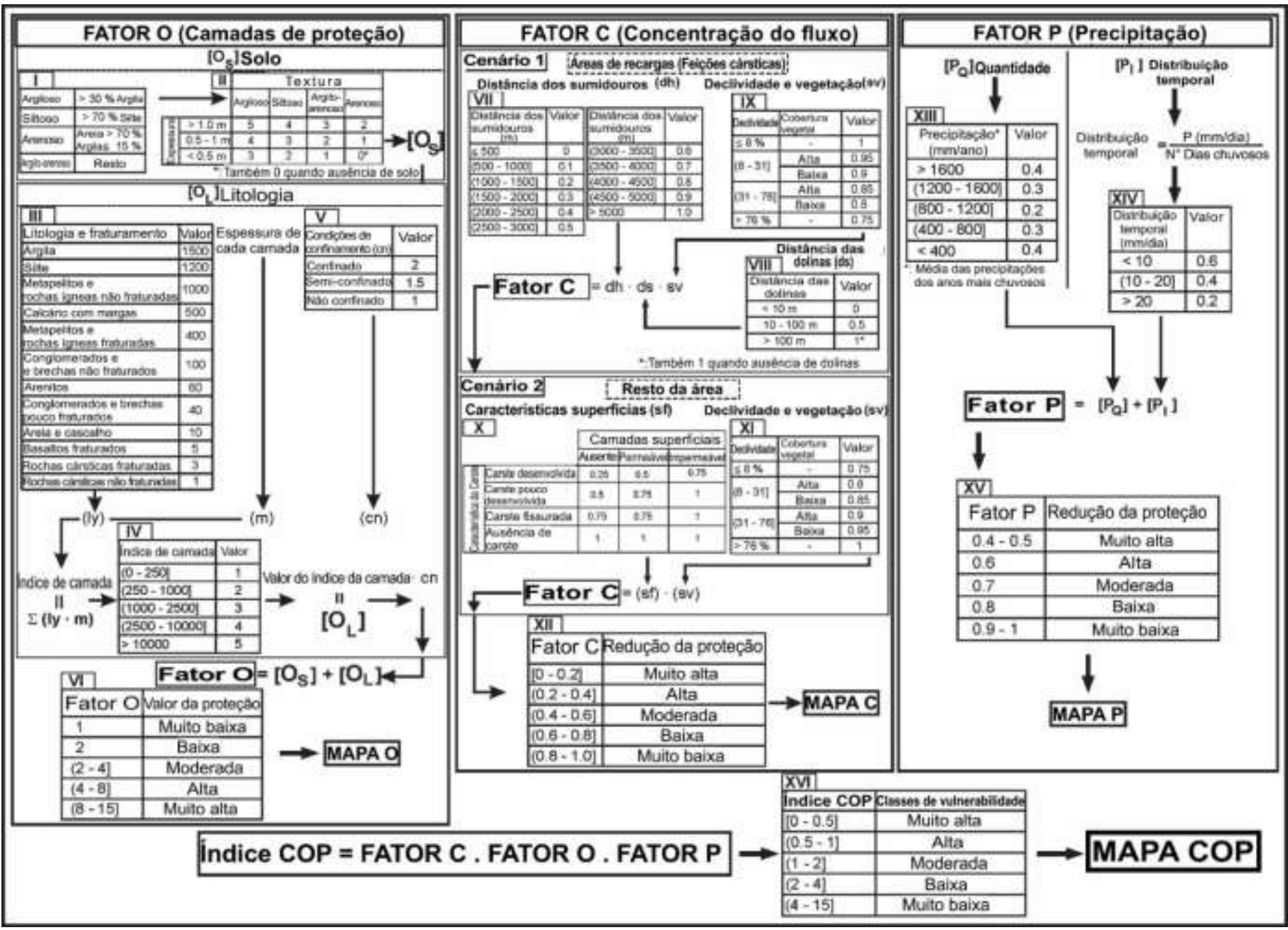

Fonte: modificado de Vías et al. (2006)

Para a avalição do subfator solo [Os] são considerados os seguintes parâmetros: textura, distribuição de tamanho dos grãos e espessura. 0 subfator [OI] reflete a capacidade de atenuação de cada camada da zona insaturada do aquífero. Para a avaliação subfator [OI] os parâmetros para a sua quantificação são o tipo de rocha e o grau de fraturamento (ly), a espessura de cada camada $(\mathrm{m})$ e as condições de fraturamento às quais está submetido o aquífero (cn). O somatório do produto dos parâmetros produz o índice que está associado com a proteção do aquífero: $\Sigma$ [ly.m].cn. A capacidade de atenuação de contaminantes aumenta proporcionalmente com o aumento das camadas de proteção, ou seja, valores mais do fator (0) são correspondentes a regiões em que o grau de proteção é alta, devido a presença de um solo desenvolvido e litologias com baixa permeabilidade. 0 fator (0) é obtido pelo somatório dos subfatores solo [OS] e litologia [OL].

O fator $(\mathrm{P})$ inclui a quantidade de precipitação da área e fatores que influenciam na taxa de infiltração, como: frequência, distribuição temporal, duração e intensidade de eventos de chuvas extremos. Esses fatores determinam a capacidade da precipitação no transporte de contaminantes da superfície para o aquífero. Quanto maior for a capacidade de transporte de contami- nantes, maior será a vulnerabilidade do aquífero. Portanto, o fator $(\mathrm{P})$ é avaliado por dois subfatores: quantidade de precipitação $[\mathrm{Pq}]$ e distribuição temporal da precipitação [Pi].

O subfator $[\mathrm{Pq}]$ representa o efeito da quantidade das chuvas, relacionado à média anual de chuvas das séries históricas dos anos úmidos, e a recarga anual sobre a vulnerabilidade do aquífero. É considerada a precipitação média dos anos úmidos, pois é quando o nível piezométrico está mais próximo da superfície topográfica e o aquífero, nesse momento, é mais vulnerável à contaminação. Vários métodos (PI e DRASTIC) consideram que a vulnerabilidade do aquífero aumenta com o aumento da quantidade de chuva e o consequente aumento da recarga do aquífero, porém, outros métodos (SINTACS) propõem que com o aumento da quantidade de chuva, as taxas mais elevadas de recarga proporcionam uma maior diluição do contaminante e, consequentemente, a vulnerabilidade diminui. Portanto, fica estabelecido que com o aumento da precipitação até cerca de 800 a $1200 \mathrm{~mm}$, a vulnerabilidade do aquífero à contaminação tende a aumentar por consequência do aumento do transporte de contaminantes para o aquífero, sendo mais importante do que o processo de diluição. No entanto, quando a precipitação anual é superior a $1200 \mathrm{~mm}$, o processo de diluição de potenciais contaminantes é mais provável do que o transporte destes e, por conseguinte, a 
vulnerabilidade tende a ser menor. Quando a precipitação é superior a $1600 \mathrm{~mm}$, a capacidade de proteção do aquífero não se modifica, permanecendo de certa forma, constante.

O subfator [Pi] representa a distribuição temporal da precipitação em um determinado período de tempo, isto é, indica a intensidade da precipitação. Para estimar esse subfator é considerado o número obtido da divisão da precipitação anual pelo número de dias chuvosos. Portando, quanto maior a precipitação anual e o menor número de dias chuvosos, maior será a vulnerabilidade do aquífero, isto é, aumenta o escoamento para as feições cársticas que favorece a concentração do fluxo para o aquífero. Valores mais altos do fator $(P)$ indicam um menor impacto sobre 0 nível de proteção conferido pelo fator (0). No entanto os valores mais baixos indicam que a precipitação, como uma função da quantidade e intensidade, diminui a proteção conferida pelo fator $(0)$ e aumenta a vulnerabilidade do aquífero. O fator (P) é obtido pelo somatório dos subfatores quantidade de precipitação $[\mathrm{Pq}]$ e distribuição temporal da precipitação [Pi].

Vías et al. (2006) ressaltou que a base conceitual deste método é avaliar a proteção natural das águas subterrâneas determinada pelas propriedades dos solos e da zona não-saturada e, estimar como essa proteção pode ser modificada pelo processo de infiltração - difusa ou concentrada - e pelas diferentes condições climáticas. 0 resultado é agrupado em cinco classes de variação de vulnerabilidade (muito alta, alta, moderada, baixa e muito baixa), com índices que variam em intervalos de 0 a 15, determinadas pela seguinte equação.

$$
\text { Índice }=\text { C.O.P }
$$

\section{RESULTADOS E DISCUSSÕES}

As feições cársticas apresentadas na figura 6 foram individualizadas a partir da interpretação de imagens oriundas do banco de imagens do software ArcGIS 10.1 e levantamento de campo.
Esse banco de dados agrupa imagens de diversos satélites e empresas, entre os quais, Esri, DigitalGlobe, GeoEye, Earthstar Geographics, CNES/Airbus DS, USDA, USGS, AEX, Getmapping, Aerogrid, IGN, IGP e Swisstopo, com resoluções de até 15m x 15m na área de estudo.

A área é largamente carstificada, com uma vasta concentração de dolinas, com uma área total de $5,43 \mathrm{~km}^{2}$ (Figura 3). As dolinas apresentam tamanhos que variam de dezenas a centenas de metros. Na porção norte as dolinas apresentam um tênue alinhamento, que possivelmente estão seguindo zonas de fraqueza das rochas, relacionadas a fraturas e condutos cársticos. A porção leste apresenta uma intensa redução do processo de carstificação, contrastando com o restante da área, que pode estar ligado ao processo de deposição de sedimentos siliciclásticos oriundos das rochas do Grupo Chapada Diamantina.

O mapa de declividade da área de estudo foi produzido por meio do software ArcGIS 10.1, com base no modelo digital do terreno (MDT), a partir de imagens de SRTM (Shuttle Radar Topography Mission) disponibilizadas pelo INPE (Instituto Nacional de Pesquisas Espaciais), através do projeto Topodata. Os valores da declividade não passam de 6\% (Figura 4).

Foram observados os dois cenários relacionados ao fator $\mathrm{C}$ descritos na metodologia utilizada para o mapeamento da vulnerabilidade. Nas áreas relacionadas ao Cenário 1, onde ocorre o fluxo concentrado de infiltração, a avaliação do fator $\mathrm{C}$ considera a distância da área de recarga ao sumidouro (dh) e às dolinas (ds) e a influência da declividade (s) e da vegetação (v). Das feições cársticas relacionadas ao cenário 1 , foram identificadas e mapeadas com base em uma análise morfológica do terreno, através do uso de imagens de satélites e trabalho de campo, a presença de dolinas. Nesse caso os valores atribuídos às dolinas (dh), até um raio de 10 metros do centro é atribuído o valor 0 e de um raio entre 10 e $100 \mathrm{~m}$ é atribuído o valor 0,5. O valor atribuído ao subfator de declividade e cobertura vegetal (sv) é 1,0, já que a declividade, com base no mapa de modelo digital do terreno (MDT), está abaixo de $8 \%$. 
Figura 3 - Mapa da distribuição das feições cársticas do aquífero Salitre no município de Cafarnaum

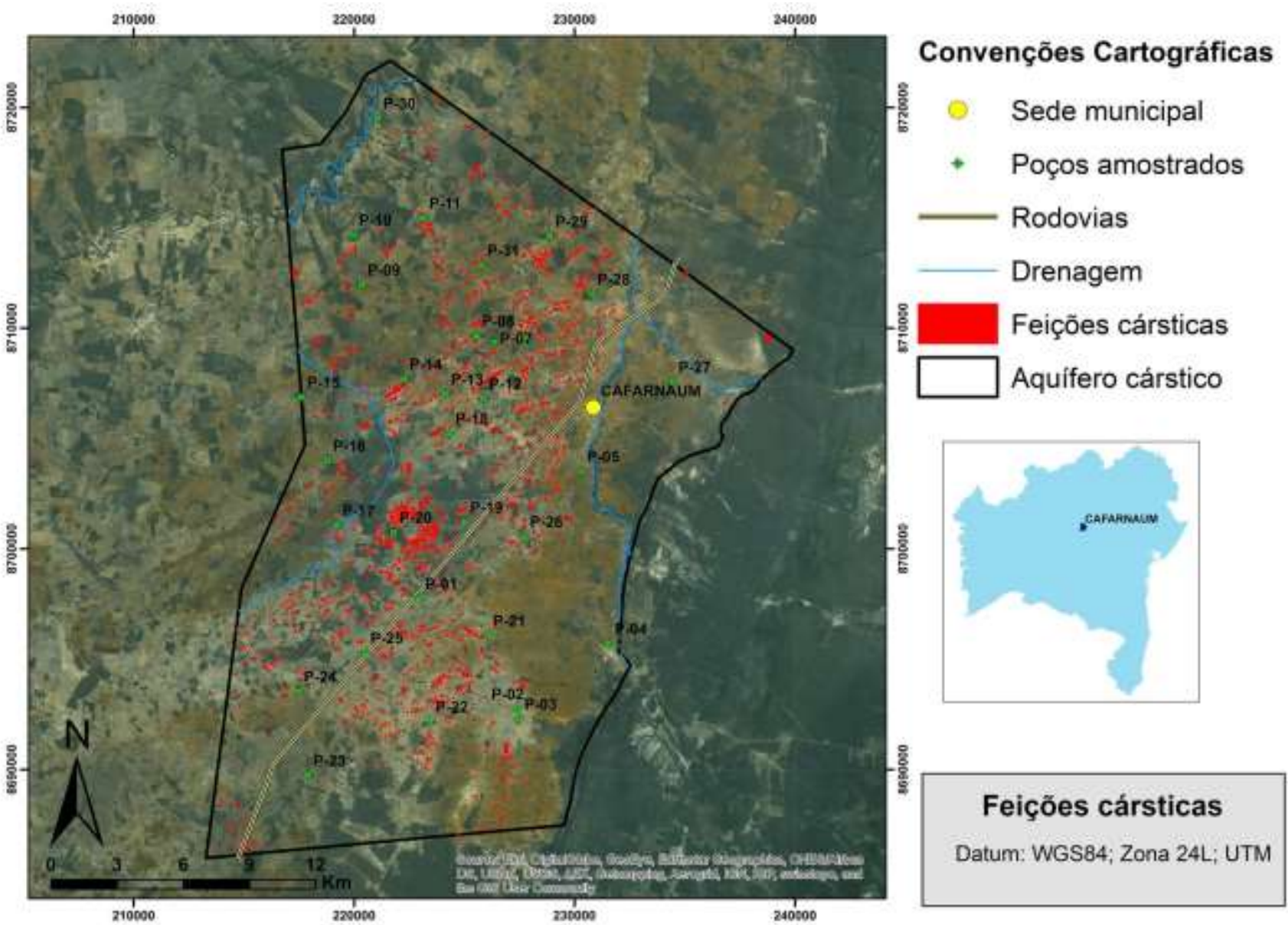

Fonte: Elaboração dos autores

Figura 4 - Mapa de declividade da área de estudo

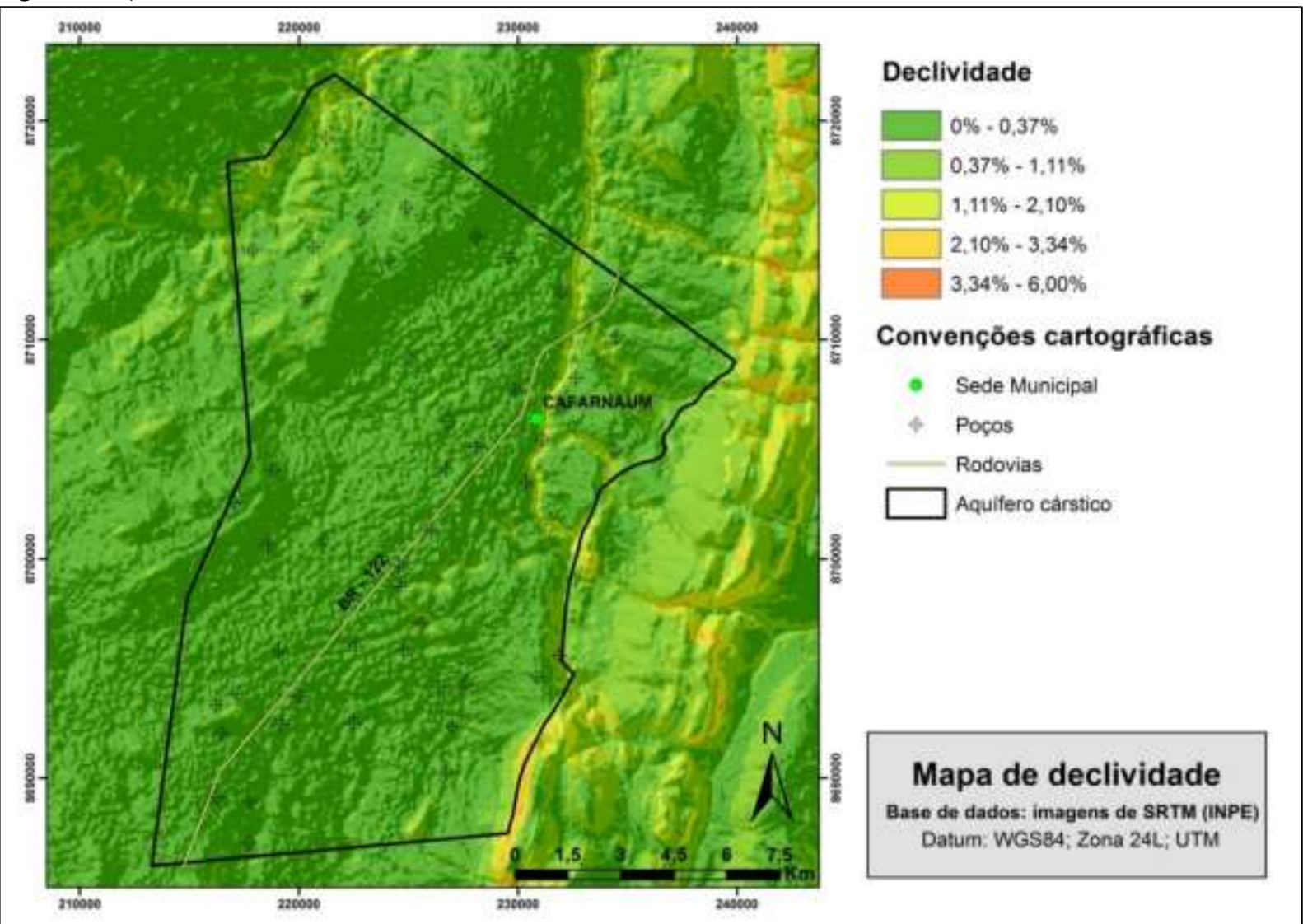

Fonte: Elaboração dos autores 
Nas áreas relacionadas ao Cenário 2, no restante da área de estudo onde ocorre a infiltração difusa, considera a presença de feições cársticas e camadas superficiais (sf) e a influência da declividade (s) e da vegetação (v). Não foi mapeado e identificado nenhuma ocorrência de carste devido a falta de afloramento das rochas que compõem o aquífero, então para o subfator presença de feições cársticas e camadas superficiais (sf) foi atribuído o vaIor 1,0 e ao subfator de declividade e cobertura vegetal (sv) foi indicado o valor 0,75 , já que a declividade do terreno está abaixo de $8 \%$.

Dentro do domínio relevante ao cenário 1, o valor estimado para o fator $\mathrm{C}$ causa uma redução da proteção do aquífero de "muito alta”, devido a presença do fluxo concentrado de infiltração nas dolinas, então a proteção natural dada pelo fator 0 é ignorada nessas áreas. Já no domínio relacionado ao cenário 2, o valor medido para o fator C causa uma redução da proteção "baixa".

O fator O é avaliado por dois subfatores: subfator de solo (Os) e subfator litologia das camadas da zona insaturada [OI]. As informações sobre o tipo de solo, espessura e litologia das camadas da zona insaturada foram retiradas das fichas técnicas dos poços perfurados e sua distribuição espacial foi obtida através da interpolação desses dados através de Krigagem Ordinária. Os parâmetros que entram em jogo na avaliação do subfator (Os) são a textura e a espessura do solo. 0 valores para esse subfator variam de 0 , para a ausência de solo ou solo arenoso com menos de meio metro de espessura, até 5 , para solos argilosos com mais de 1 metro de espessura.

O subfator (OI) da litologia reflete a capacidade de atenuação de cada camada da zona insaturada. Três parâmetros contribuem para sua avaliação: o tipo de rocha e o grau de fraturamento (ly), a espessura de cada camada $(\mathrm{m})$ e a condição de confinamento do aquífero (cn). Os valores referentes a esse fator variam de $1 \mathrm{a}$ 4, onde o valor mínimo está associado a rochas cársticas fraturadas ou não, e o valor máximo está associado à presença de camadas de argila na zona insaturada. 0 aquífero estudado não é confinado. $O$ valor final estimado para o fator $O$ indica o grau de proteção do aquífero "alta" a " muito baixa".
$O$ fator $\mathrm{P}$ é avaliado por dois subfatores: quantidade de precipitação $(\mathrm{Pq})$ e distribuição temporal da precipitação (Pi). Para sua determinação, foram utilizados os dados de precipitação da região para o período de 1964 a 1991 fornecidos pela ANA (Agência Nacional de Águas). 0 subfator (Pq) está relacionado à média da quantidade de chuva dos anos mais chuvosos. Para a região essa média é de $726 \mathrm{~mm}$, que corresponde ao valor 0,3. Já o subfator ( $\mathrm{Pi}$ ) é referente aos dias de chuva dos anos mais chuvosos, ou seja, a intensidade da precipitação. Para a região essa média é de 30 dias chuvas por ano, portanto $32 \mathrm{~mm}$ de chuva por dia, que é atribuído o valor 0,2. 0 valor final estimado para o fator $\mathrm{P}(0,5)$ está associado a uma redução da proteção "muito alta".

A aplicação da metodologia COP, na avaliação da vulnerabilidade do aquífero estudado, permitiu a subdivisão da área em quatro classes de vulnerabilidade (Figura 5): muito alta - 12,5\%, 70,20 $\mathrm{km}^{2}$ da área; alta - 0,7\%, 4,0 km² da área; moderada - 28,0\%, $154,41 \mathrm{~km}^{2}$ da área; baixa - 58,7\%,330,00 km² da área.

A delimitação da classe de vulnerabilidade muito alta está diretamente relacionada ao cenário 1 do fator $\mathrm{C}$. Este cenário é formado pela presença de dolinas, onde a infiltração se faz de forma concentrada e direta através dos condutos oriundo da dissolução das rochas carbonáticas. Neste cenário, a proteção do aquífero referente proporcionada pelas camadas da zona insaturada e pelo solo (fator 0 ) é totalmente ignorada.

Já a delimitação das classes de vulnerabilidade alta, moderada e baixa, onde a infiltração ocorre de forma difusa (Cenário 2 do fator $\mathrm{C}$ ), a vulnerabilidade depende essencialmente do fator 0 . Nas áreas com vulnerabilidade alta acorre a presença de solos pouco espessos ou a ausência do mesmo, diminuindo a capacidade de proteção do aquífero. As áreas com o vulnerabilidade moderada e alta foi determinada a partir da existência de solos espessos e impermeáveis, e também devido à ocorrência de camadas argilosas na zona insaturada, aumentando o fator de proteção do aquífero. $O$ fator $P$ não contribui diretamente no zoneamento das classes de vulnerabilidade, devido ao pequeno tamanho da área de estudo e da presença de apenas um regime de precipitação. 
Figura 5 - Mapa de Vulnerabilidade Intrínseca à Contaminação pelo método COP

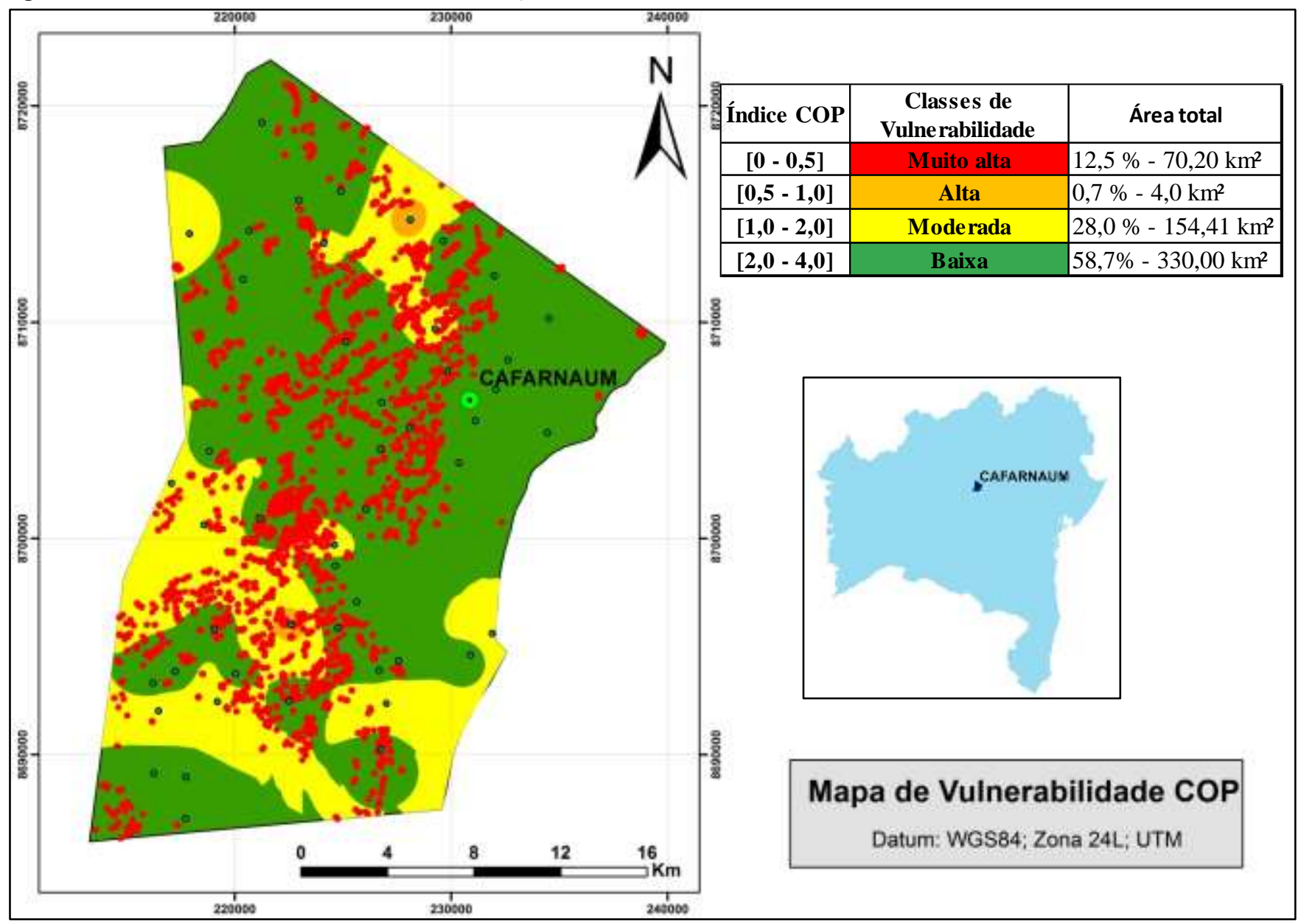

Fonte: Elaboração dos autores

\section{CONCLUSÃO}

A partir da análise do mapa de vulnerabilidade intrínseca a contaminação do aquífero cárstico Salitre no município de Cafarnaum, permitiu a delimitação de 4 classes de vulnerabilidade na área: muito alta $\left(12,5 \%-70,20 \mathrm{~km}^{2}\right)$, alta $\left(0,7 \%-4,0 \mathrm{~km}^{2} \mathrm{da}\right.$ área), moderada $\left(28,0 \%\right.$ - $154,41 \mathrm{~km}^{2}$ da área) e baixa $(58,7 \%$ $330,00 \mathrm{~km}^{2}$ da área). A individualização dessas classes de vulnerabilidade foi obtida através da análise dos parâmetros descritos na metodologia COP.

Para o fator C, a individualização das feições cársticas (dolinas) e de sua área de influência, até 100 metros da borda da dolina, é o fator que teve um papel significativo para a delimitação da classe de vulnerabilidade muito alta do índice COP gerados na área. As dolinas fornecem conexão direta do aquífero com a superfície, acarretando no transporte de contaminantes para a zona saturada, sem sofrer nenhum tipo de retenção química ou física na zona insaturada. A ausência de outras feições cársticas, devido à falta de afloramentos e consequentemente, a baixa intensidade dos processos de carstificação nas demais áreas do aquífero, influenciou a delimitação da classe de vulnerabilidade moderada a baixa no índice COP. A baixa declividade na área de pesquisa foi um fator que não teve influência significativa na delimitação das classes de vulnerabilidade.

O fator 0 é totalmente ignorado nas áreas de vulnerabilidade muito alta, pois, na presença de dolinas, ocorre a concentração do fluxo de recarga do aquífero. Para as áreas com vulnerabilidade moderada a baixa, o fator $O$ teve um papel fundamental para a proteção do aquífero, devido à ocorrência de solos espessos e impermeáveis, além da presença de camadas argilosas na zona insaturada.

O fator $\mathrm{P}$ é constante e não contribui de forma direta na delimitação das classes de vulnerabilidade, em função do pequeno tamanho da área de estudo e a presença de apenas um regime de precipitação.

O mapa de vulnerabilidade intrínseca à contaminação do aquífero cárstico Salitre no município de Cafarnaum, apresentado nessa dissertação, pode e deve ser utilizado para o planejamento e gestão hídrica e territorial pelos agentes municipais e estaduais, uma vez que delimita as áreas mais vulneráveis à contaminação, como um indicativo de que devem ser áreas protegidas, de forma a viabilizar programas de gestão comprometidos com a preservação ambiental.

\section{REFERÊNCIAS}

ANA - AGÊNCIA NACIONAL DE ÁGUAS. Portal Hidroweb. Disponível em: <http://www.snirh.gov.br/hidroweb/>. Acesso em 1 de janeiro de 2017.

DOMINGUEZ, J. M. L. As Coberturas do Cráton do São Francisco: Uma Abordagem do Ponto de Vista da Análise de Bacia. In: SIMPÓSIO CRÁTON DO SÃO FRANCISCO, 2., 1993 Salvador. Anais..., p. 173-159, 1993. 
DOMINGUEZ, J. M. L. As Coberturas Plataformais do Proterozóico Médio e Superior. In: BARBOSA, J. S. F.; DOMINGUEZ, J. M. L., Geologia da Bahia. 1.ed. Salvador. $1^{\text {a }}$ Parte. cap.V, p.105-125, 1996.

FIGUEIREDO, F. T. Fácies sedimentares e proveniência da Formação Bebedouro, Neoproterozóico (BA). 2008. Dissertação (Mestrado em Geologia) - Instituto de Geociências, Universidade de São Paulo, São Paulo.

FORD, D.; WILLIAMS, P.D. Karst hydrogeology and geomorphology. Chichester: Wiley, 2007, 562 p.

FOSTER, S. S. D.; HIRATA, R.; GOMES D.; D' ELIA M.; PARIS, M. Groundwater Quality Protection: A Guide for Water Service Companies, Municipal Authorities and Environment Agencies. The International Bank for Reconstruction and Development/The World Bank. Ed. brasileira: SERVMAR, São Paulo, 2002. 114 p.

GUERRA, A. M. Processos de carstificação e hidrogeologia do Grupo Bambuí na região de Irecê - Bahia. 1986. 132p. Tese (Doutorado em Geologia) - Instituto de Geociências, Universidade de São Paulo, São Paulo.

GUIMARÃES, J. T. A Formação Bebedouro no Estado da Bahia: faciologia, estratigrafia e ambientes de sedimentação. 1996. 155p. Dissertação (Mestrado em Geologia) - Instituto de Geociências, Universidade Federal da Bahia, Bahia.

INDA, H. A. V.; BARBOSA, J. F. Texto explicativo para o mapa geológico do estado da Bahia ao milionésimo. Salvador: CPRM, 1978. 137 p.

IVÁN, V.; MÁDL-SZÕNYI, J. State of the art of karst vulnerability assessment: overview, evaluation and outlook. Environmental Earth Sciences, v. 76, p. $76-112,2017$.
MISI, A. O Grupo Bambuí no estado da Bahia. In: INDA, H. A. V. (Ed.) Geologia e recursos minerais do Estado da Bahia: textos básicos. Salvador: Secretaria das Minas e Energia, Superintendência de Geologia e Recursos Minerais, v. 1, p.119- 154, 1979.

NOSSA, T. C. B.. Avaliação da vulnerabilidade do aquífero cárstico Salitre - Bahia, através de análises hidroquímicas, isotópicas e aplicação da metodologia COP. 2011. 226p. Tese (Doutorado em Geologia) - Instituto de Geociências, Universidade Federal da Bahia, Bahia.

PEDREIRA, A. J.; ROCHA, A. J. D.; COSTA, I. V. G.; MORAIS FILHO, J. C. Projeto Bacia de Irecê-II: relatório final. Salvador: CPRM, 1987.

SAMPAIO, A. R. Programa Levantamentos Geológicos Básicos do Brasil PLGB. Jacobina - Folha SC 24-y-C, Estado da Bahia. Escala 1:250.000. Brasília: CPRM/DIEDIG/DEPAT, 2001.

SANTOS, R. A. Hidrogeoquímica dos domínios cársticos de Irecê, Bahia Brasil. 2017. 97 f. Tese (Doutorado em Geologia) - Instituto de Geociências, Universidade Federal da Bahia, Bahia, 2017.

SEI - Superintendência de Estudos Econômicos e Sociais da Bahia. Estatística dos municípios baianos. Salvador. v. 20, 382 p., 2011

VÍAS, J. M.; ANDREO, B.; PERLES, M. J.; CARRASCO, F.; VADILLO, I.; JIMÉNEZ, P. Proposed method for groundwater vulnerability mapping in carbonate (karstic) aquifers: the COP method. Hidrogeology Journal, v. 14, n. 6, p. 912-925, 2006.

VRBA, J.; ZAPOROZEC, A. Guidebook on mapping groundwater vulnerability. Hannover: H. Heise, 1994, 131 p. 